\title{
Comparison surface characteristics and chemical composition of conventional metallic and Nickel-Free brackets
}

\section{Ricardo Lima SHINTCOVSK ${ }^{(a)}$ Luegya Amorim Henriques KNOP(a) \\ Luiz Gonzaga GANDINI Jr(a) Lidia Parsekian MARTINS(a) Aline Segatto PIRES(b)}

(a) Universidade Estadual de São Paulo UNESP, School of Dentistry at Araraquara, Department of Pediatric Clinic, Araraquara, SP, Brazil.

(b) Universidade Federal do Rio Grande do Sul - UFRGS, School of Dentistry, Department of Dental Materials, Porto Alegre, RS, Brazil.

Declaration of Interests: The authors certify that they have no commercial or associative interest that represents a conflict of interest in connection with the manuscript.

Corresponding Author:

Ricardo Lima Shintcovsk

E-mail: ricshintcovsk@yahoo.com.br

DOI: 10.1590/1807-3107BOR-2015.vol29.0022

Submitted: Feb 19, 2014

Accepted for publication: Sep 23, 2014

Last revision: Dec 01, 2014

\begin{abstract}
This study aims at comparing conventional and nickelfree metal bracket surface characteristics with elemental composition by scanning electron microscopy (SEM), using energy dispersive spectroscopy (EDS). The sample consisted of 40 lower incisor brackets divided into four groups: $\mathrm{ABZ}=$ conventional brackets, Kirium Abzil $3 M^{\circledR}(\mathrm{n}=10) ; \mathrm{RL}=$ conventional brackets, Roth Light Morelli ${ }^{\circledR}(\mathrm{n}=10)$; $\mathrm{NF}=$ nickel-free brackets, Nickel-Free Morelli ${ }^{\circledast}(\mathrm{n}=10)$; and RM = nickel-free brackets, Roth Max Morelli ${ }^{\circledR}(\mathrm{n}=10)$. Qualitative evaluation of the bracket surface was performed using SEM, whereby surface features were described and compared. The elemental composition was analyzed by EDS. According to surface analysis, groups ABZ and RL showed a homogeneous surface, with better finishing, whereas the surfaces in groups NF and RM were rougher. The chemical components with the highest percentage were $\mathrm{Fe}, \mathrm{Cr}$ and $\mathrm{C}$. Groups NF and MR showed no nickel in their composition. In conclusion, the bracket surface of the $\mathrm{ABZ}$ and RL groups was more homogeneous, with grooves and pores, whereas the surfaces in groups NF and RM showed numerous flaws, cracks, pores and grooves. The chemical composition analysis confirmed that the nickel-free brackets had no $\mathrm{Ni}$ in their composition, as confirmed by the manufacturer's specifications, and were therefore safe to use in patients with a medical history of allergy to this metal.
\end{abstract}

Keywords: Orthodontic Brackets; Nickel; Hypersensitivity; Microscopy.

\section{Introduction}

Although the materials applied in orthodontics have evolved greatly, are prescribed in several different types, and compose a variety of bracket brands, metallic materials are still very commonly used because of their physical and chemical characteristics, as well as their mechanical properties. Bearing this in mind, these materials have been researched intensely throughout the years. ${ }^{1}$

In regard to the physical and chemical characteristics of these materials, there is a diversity of ferroalloys in brackets, wires, bands, accessories and other related appurtenances, such as cobalt-chromium alloy (Cr-Co), stainless steel and titanium, all having nickel (Ni) as one of their main components. ${ }^{2,3}$

Zinelis et al. ${ }^{4}$ describe the elemental composition of the brazing alloy of four representative orthodontic brackets, namely, Gemini brackets (3M Unitec): Ni 83.98\%, Si 6.46\%, Fe 5.90\% and Cr 3.52\%; MicroLoc (GAC): 
Ag 42.82\%, Au 32.14\%, Cu 24.53\% and Mg 1.12\%; OptiMESHxrt (Ormco): Au 67.79\%, Fe 15.69\%, Ni $13.01 \%$ and $\mathrm{Cr} 4.01 \%$; and Ultratrim (Dentarum): $\mathrm{Ag}$ 87.97\%, Cu 10.51\%, Mg 1.29\% and Zn 1.13\%. Their findings showed that different brazing materials were used in making the different brands; thus different performances can be expected in intraoral exposure.

Nickel acts as a primary stabilizer in these ferroalloys; nevertheless, its atoms are not often linked, and can be released into the oral environment, raising questions as to material compatibility. ${ }^{2,5}$

Ferroalloys release $\mathrm{Ni}$ and $\mathrm{Cr}$ ions when in contact with the oral cavity, since they are subject to corrosion. ${ }^{3}$ Corrosion represents metal loss or conversion into oxide. In the humid environment of an oral cavity, all alloys are susceptible to corrosion, if only to some extent. ${ }^{6}$ Menezes et al..$^{7}$ analyzed structural and chemical alterations in several metallic brackets, and observed that the wrinkled surface of new brackets makes them more susceptible to the corrosive process, and consequently the release of metallic ions.

Several factors may interfere in the process of releasing ions: manufacturing method, type of alloy, and surface characteristics of the accessory, ${ }^{7}$ as well as characteristics of the environment with which the component comes into contact, such as composition, temperature, $\mathrm{pH}$, bacterial flora, enzymatic activity and presence of proteins. ${ }^{8}$ Additional factors include use (aging) in the face of adversities, such as stress, thermal treatment, recycling and reuse of components, and others. ${ }^{9}$

Dolci et al. ${ }^{10}$ researched the release of $\mathrm{Ni}, \mathrm{Cr}$, and iron $(\mathrm{Fe})$ ions in vitro, and concluded that there was a positive relationship between time and ion release. This relationship was also observed by Sfondrini et al. ${ }^{11}$ and Huang et al. ${ }^{9}$

Health professionals, especially orthodontists, should broaden their knowledge of material components of orthodontic use that can cause patients to have an allergic reaction. Ni has already proven to have a significant role in dermatitis and hypersensitivity reactions, ${ }^{3,11,12}$ and it has been reported that women are more affected than men.,13

The sensitization caused by Ni can be enhanced by mechanical irritation, skin maceration and/or oral mucosal lesions, which may frequently occur in orthodontic treatment. ${ }^{14}$ According to Rahilly and Price, ${ }^{12}$ contact dermatitis caused by $\mathrm{Ni}$ is the response of an immunological reaction to type IV hypersensitivity in two distinguished stages. The sensitization phase is when the body first comes in contact with $\mathrm{Ni}$ (allergen), followed by recognition and response. This stage may present no symptoms. The induction phase occurs when the body is newly exposed to nickel, which triggers the entire clinical reaction.

A precise diagnosis of allergy to $\mathrm{Ni}$ is highly relevant since lesions caused by contact stomatitis may be variable and visible. Itching has not been found to be a commonly reported symptom. Extraoral reactions occur in greater number than than intraoral reactions. ${ }^{1}$

Vreeburg et al..$^{14}$ report the importance of differential diagnoses of allergy to $\mathrm{Ni}$, since other reactions similar to that of Ni may occur, such as candidiasis, herpetic stomatitis and mouth ulcers, or else allergy to Ni may be confounded with allergies to other materials, such as latex and acrylic.

Ehrnrooth and Kerosuo ${ }^{13}$ reported a clinical case involving a thirty-four-year-old female patient who presented a characteristic allergic reaction of pruritus on the face, eruption of small reddish papules on the chin, cheeks and neck, as well as eye symptoms, a week after the insertion of braces.

The biocompatible nature of ferroalloys containing $\mathrm{Ni}$ is questionable, since this component is known for presenting allergenicity, as well as carcinogenic, mutagenic and cytotoxic effects. ${ }^{7}$ Nevertheless, this issue still raises great discussion in literature. Nickelfree brackets (with no or low content of $\mathrm{Ni}$ ) were required as a treatment alternative, because of the need to use materials that do not release or contain $\mathrm{Ni}$ in their structural composition. A European company called Dentaurum ${ }^{\circledR}$ presented an entirely biocompatible titanium bracket at the Annual Convention of the American Dental Association in $1995 .{ }^{15}$ Representing the Brazilian market, the Morelli $^{\circledR}$ company provides brackets promoted as nickel-free, with an accepted $0.2 \%$ percentage of $\mathrm{Ni}$ in their composition. The Abzil $3 M^{\circledR}$ company does not have nickel-free metallic brackets, and recommends the use of ceramic brackets for patients with allergy to $\mathrm{Ni}^{12}$ 
However, the Monobloco nickel-free brackets used in this study and made by Morelli ${ }^{\circledast}$ are no longer manufactured, and have been replaced by the Roth Max Line, which was not found in the literature.

This study aims at comparing the surface characteristics of conventional metallic brackets and the new nickel-free brackets, according to chemical composition, by scanning electron microscopy (SEM) using the energy-dispersive $X$ Ray (EDX).

\section{Methodology}

This study used fourty new lower incisors brackets by Abzil $3 M^{\circledast}$ and Morelli ${ }^{\circledR}$, divided into four groups:

Group ABZ - 10 conventional brackets, Kirium by Abzil 3M ${ }^{\circledR}$ (3M Unitek, S itek, Ribeirão Preto, Brazil);

Group RL - 10 conventional brackets, Roth Light by Morelli ${ }^{\circledR}$ (Dental Morelli Ltda., Sorocaba, Brazil);

Group NF - 10 nickel-free brackets, Nickel-Free by Morelli $^{\circledR}$ (Dental Morelli Ltda., Sorocaba, Brazil);

Group RM - 10 nickel-free brackets, Roth Max by Morelli $^{\circledR}$ (Dental Morelli Ltda., Sorocaba, Brazil).

The 10 brackets from each group were mounted on stubs and analyzed by SEM (JEOL SM-6390LV, Tokyo, Japan). Each stub contained two brackets. Five stubs from each group were mounted for SEM analysis.

\section{Surface Analysis}

The surface analysis was conducted with photomicrographs obtained at 25x and 500x magnification for each bracket, after making adjustments in light, contrast and focus by an examiner. The following images were then recorded for each orthodontic accessory, according to methodology by Menezes et al. ${ }^{7}$

a. Frontal (general) - total bracket length (25x magnifiation). Arrow shows the left gingival blade area of the bracket for chemical composition analysis - Figure 1.

b. Frontal (specific) - the left gingival blade area of the bracket for chemical composition analysis (500x magnification) - Figure 2.

Only one examiner carried out qualitative assessment of the surface finish differences for all orthodontic accessories, according to each company, with characteristic descriptions and comparison among groups.

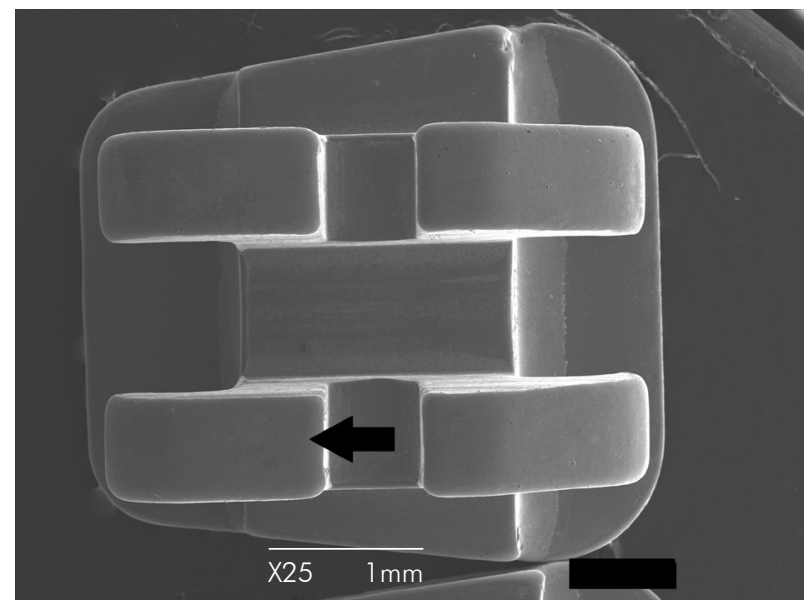

Figure 1. Frontal photomicrograph (general) at 25x magnification. Arrow pointing to the particular image generated at 500x magnification.

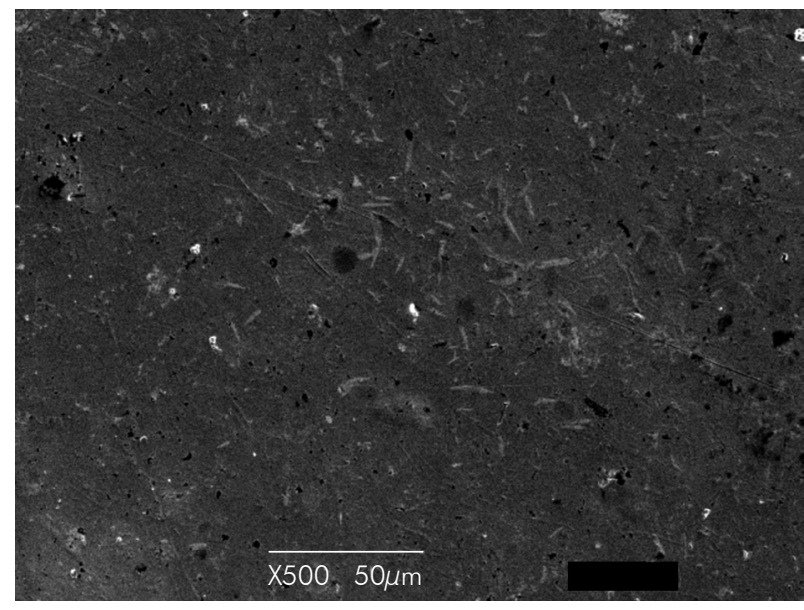

Figure 2. Frontal photomicrograph (specific) at 500x magnification.

\section{Chemical Composition Analysis}

Chemical composition analysis was carried out with an energy dispersive X-ray (EPX), an auxiliary tool available on SEM. This analysis was performed on all the brackets of all the groups. The area assessed was the buccal surface of the left gingival blade of each bracket, at 500x magnification, according to methodology by Menezes et al. ${ }^{7}$ According to this analysis, the chemical compositions for each bracket can be quantified and compared. The presence of $\mathrm{Ni}, \mathrm{Fe}, \mathrm{Cr}$, Mo and other components was assessed.

Each bracket assessed generated a file containing a table with the elements and their composition, together 
with the respective percentages. These data were tabbed and analyzed with GraphPad Prism software, version 5.04 (Graphpad Software Inc., San Diego, USA).

Each chemical element was assessed in each of the four groups. First, the Kolmogorov-Smirnov test was applied to assess the sample distribution.

The one-way parametric of Analysis of Variance (ANOVA) was applied for chemical elements that presented regular distribution, and established whether there had been any meaningful statistical difference among the groups (however, without establishing among what groups). Tukey's multiple comparisons test was then applied to identify the groups with a significant statistical difference, based on a significance level of $p<0.05$.

The chemical elements without regular distribution in the samples were assessed by the Kruskall-Wallis non-parametric test, establishing whether there had been any significant statistical difference among the groups., followed by Dunn's multiple comparison test to identify the groups with significant statistical difference, based on a significance level of $p<0.05$.

\section{Results}

\section{Surface Analysis}

The general images (25x) generated by SEM revealed more homogeneous surfaces with better quality finishes for brackets from groups ABZ and $R L$, as compared with the surfaces of brackets from groups NF and RM, which seemed to present greater rugosity.

Group ABZ revealed a larger area of imperfections for upper bracket bases. The gingival blades of these brackets presented greater rugosity than the bracket blades of the other groups, since these blades were marked with ink. The remaining areas, such as the slot and other bracket bases, revealed a more homogeneous and flatter surface. Imperfections were observed on the surface of the lateral bottom regions of brackets from group RL. The remaining areas of bases, slots and blades presented improvement in surface polishing and homogeneity.

The entire surface of the brackets from group NF presented a rougher aspect for the blades, bases and slots. The brackets from group RM also presented a rougher, less polished surface. Areas of imperfection appeared on both blades and slots. The left gingival blade of all brackets presented greater imperfections than other blades, revealing an area with more stretch marks, dimples and rugosity.

Particular images (500x) indicated that the surface of bracket blades from groups ABZ (Figure 3) and RL (Figure 4) presented an improvement in surface finish, compared with the brackets from groups NF (Figure 5) and RM (Figure 6). Stretch marks were observed on the surface of the brackets of all the groups.

The surface of the left gingival blades of the brackets from group ABZ presented predominant pores and stretch marks that were more homogeneous. A grainy aspect was observed in some brackets. Group RL presented fewer pores than group ABZ, and with a smaller diameter, making the surface look more homogeneous. However, more stretch marks and some dimples were observed.

The surface of the left gingival blades of group NF blades did not present pores. Imperfections such as multiple stretch marks and some dimples were observed. Group RM did not present any more stretch marks than groups ABZ and RL, but it did present more gaps, pores and dimples, and the surfaces presented rugosity and more imperfections than the remaining groups.

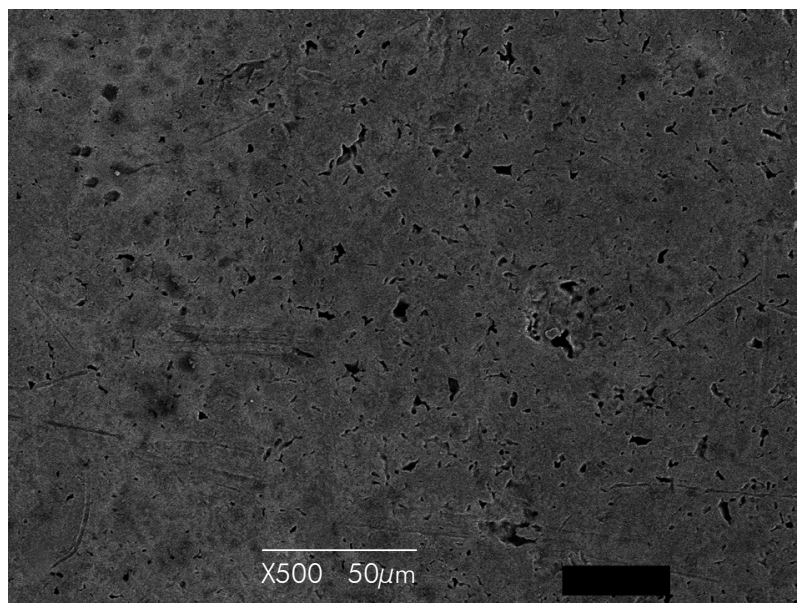

Figure 3. Photomicrograph from Group $A B Z$ at 500x magnification. 


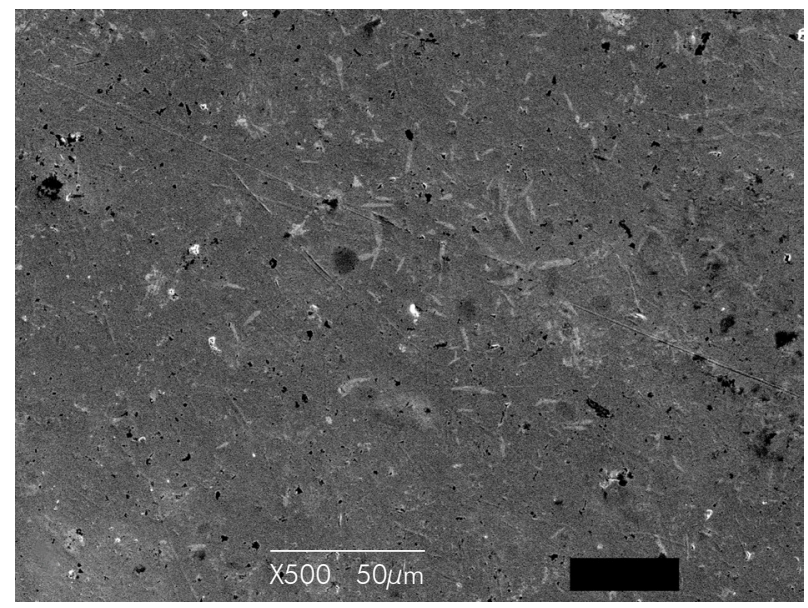

Figure 4. Photomicrograph from Group RL at 500x magnification.

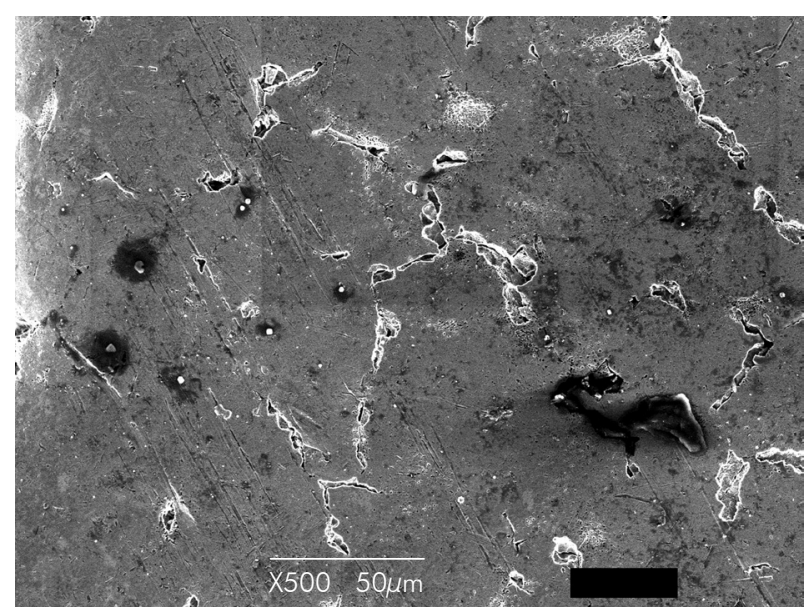

Figure 6. Photomicrograph from Group RM at 500x magnification.

\section{Chemical Composition Analysis}

Table 1 presents the means and standard deviation of percentages of Iron (Fe), Chrome $(\mathrm{Cr})$, Carbon (C) and Silicon (Si), according to bracket type.

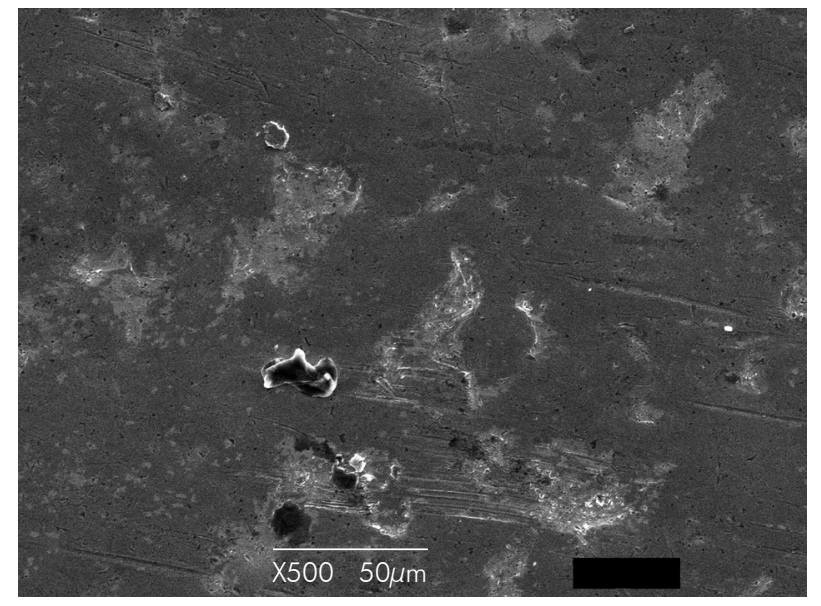

Figure 5. Photomicrograph from Group NF at 500x magnification.

Among all the groups, the chemical components with the highest percentages were Fe and Cr. Carbon (C) was present in all the groups as well. The components with the lowest percentages were $\mathrm{Mn}$, $\mathrm{Ni}, \mathrm{Mo}, \mathrm{Co}, \mathrm{Al}$ and $\mathrm{Si}$ (Table 2).

Brackets from group ABZ presented more Fe and $C$ than brackets from group RM $(p<0.05)$. Group RM presented significantly more $\mathrm{Cr}$ than group RL. The silicon (Si) percentage was different among all groups, except when comparing RM with RL.

Groups NF and RM did not present nickel in their compositions. When compared with RL, these groups presented a statistical difference. Group ABZ did not differ statistically from the remaining groups.

Nickel-free groups (NF and RM) contained manganese (Mn) and molybdenum (Mo) in their composition, differing significantly from the remaining groups (ABZ and RL), which did not present these components in their compositions.

Components $\mathrm{Co}$ and aluminum (Al) did not present a statistical difference among the groups assessed.

Table 1. Means and standard deviation for percentages of Iron (Fe), Chrome ( $\mathrm{Cr}$ ), Carbon (C) and Silicon (Si), according to the bracket group assessed.

\begin{tabular}{lccccc}
\hline & $\mathrm{ABZ}$ & $\mathrm{RL}$ & $\mathrm{NF}$ & $\mathrm{RM}$ & $\mathrm{P}$ \\
$\mathrm{Fe}$ & $69.22(2.10)^{\mathrm{a}}$ & $66.37(5.24)^{\mathrm{ab}}$ & $64.73(2.53)^{\mathrm{ab}}$ & $63.72(1.75)^{\mathrm{b}}$ & $0.039^{*}$ \\
$\mathrm{Cr}$ & $18.37(1.58)^{\mathrm{ab}}$ & $16.86(1.36)^{\mathrm{a}}$ & $17.67(0.73)^{\mathrm{ab}}$ & $19.08(0.83)^{\mathrm{b}}$ & $0.023^{*}$ \\
$\mathrm{C}$ & $9.26(1.65)^{\mathrm{a}}$ & $5.36(4.47)^{\mathrm{ab}}$ & $3.68(1.60)^{\mathrm{ab}}$ & $2.55(1.25)^{\mathrm{b}}$ & $0.001^{*}$ \\
$\mathrm{Si}$ & $0.00(0.00)^{\mathrm{a}}$ & $0.83(0.12)^{\mathrm{b}}$ & $0.41(0.37)^{\mathrm{c}}$ & $0.92(0.19)^{\mathrm{b}}$ & $<0.001^{*}$ \\
\hline
\end{tabular}

*ANOVA/Tukey. Values followed by the same letter do not differ $(p<0.05)$. Differents letters represented statiscal difference. 
Table 2. Means and standard deviation. Ranks for percentages of Nickel (Ni), Manganese (Mn), Molybdenum (Mb), Cobalt (Co) and Aluminum (Al), according to the bracket group assessed.

\begin{tabular}{ccccccc}
\hline & & ABZ & RL & NF & RM & P \\
\hline $\mathrm{Ni}$ & $\begin{array}{l}\text { Mean (DP) } \\
\text { Mean rank }\end{array}$ & $1.76(1.40)^{\mathrm{ab}}$ & $8.20(1.20)^{\mathrm{a}}$ & $0.00(0.00)^{\mathrm{b}}$ & $0.00(0.00)^{\mathrm{b}}$ & $<0.001^{* *}$ \\
$\mathrm{Mn}$ & $\begin{array}{l}\text { Mean (DP) } \\
\text { Mean rank }\end{array}$ & $0.00(0.00)^{\mathrm{a}}$ & $0.00(0.00)^{\mathrm{a}}$ & $9.21(0.89)^{\mathrm{b}}$ & $9.84(0.98)^{\mathrm{b}}$ & $<0.001^{* *}$ \\
$\mathrm{Mo}$ & $\begin{array}{l}\text { Mean (DP) } \\
\text { Mean rank }\end{array}$ & $0.00(0.00)^{\mathrm{a}}$ & $0.00(0.00)^{\mathrm{a}}$ & $3.70(0.37)^{\mathrm{b}}$ & $3.88(0.33)^{\mathrm{b}}$ & $<0.001^{* *}$ \\
$\mathrm{Al}$ & $\begin{array}{l}\text { Mean (DP) } \\
\text { Al }\end{array}$ & $0.45(0.70)^{\mathrm{a}}$ & $0.00(0.00)^{\mathrm{a}}$ & $0.18(0.37)^{\mathrm{a}}$ & $0.00(0.00)^{\mathrm{a}}$ & $0.202^{* *}$ \\
& $\begin{array}{l}\text { Mean rank } \\
\text { Mean (DP) }\end{array}$ & $0.04(0.10)^{\mathrm{a}}$ & $0.37(0.31)^{\mathrm{a}}$ & $0.17(0.37)^{\mathrm{a}}$ & $0.00(0.00)^{\mathrm{a}}$ & $0.055^{* *}$ \\
\hline
\end{tabular}

**Kruskal Wallis/Dunn. Values followed by the same letters do not differ $(p<0.05)$. Differents letters represented statiscal difference.

\section{Discussion}

Bracket surfaces and chemical compositions were assessed in this study to determine whether nickelfree brackets indeed have no $\mathrm{Ni}$, in order to seek safer treatments for patients with an allergy to this chemical component.

Scanning electronic microscopy (SEM) has been applied in other studies to assess the surface of brackets and other orthodontic accessories, 5,7 and has proved suitable to carry out the qualitative evaluation of surface characteristics. Energydispersive X-rays have also been used as a SEM adjunct tool in assessing the chemical composition of surfaces.

In this study, brackets from groups $\mathrm{ABZ}$ and RL presented better polishing than brackets from groups NF and RM, according to Menezes et al. ${ }^{7}$ In addition, these authors observed that the brackets made by Abzil $3 M^{\circledast}$ presented more corrosionrelated alterations when submitted to biodegradation. Furthermore, they found a predominance of $\mathrm{Fe}, \mathrm{Cr}$ and $\mathrm{Ni}$ in the composition of conventional metallic brackets, as did this study.

Petoumeno et al..$^{5}$ assessed nickel-tatanium (NiTi) wires by SEM, and observed that most wires presented surfaces with manufacturing faults; however, no areas vulnerable to corrosion were identified. Authors Kao and Huang ${ }^{16}$ also assessed the surface characteristics of NiTi wires and the stainless steel of conventional metallic brackets by SEM, and also observed surface faults associated with the manufacturing process.
The final polishing process during bracket manufacturing could interfere in the surface characteristics, making it susceptible to corrosion and, consequently, to the release of ions into the oral cavity. ${ }^{7}$

Groups ABZ and RL were composed of conventional stainless steel brackets, whereas groups NF and RM contained nickel-free brackets. This can be confirmed by this study and is in accordance with manufacturer specifications. Brackets of the latter group are suggested as safer for patients with an allergy to nickel or metals in general. Zinelis et al. ${ }^{4}$ assessed the elemental composition of the brazing alloy of four representative orthodontic brackets, and observed $83.98 \%$ of $\mathrm{Ni}$ in one of them; the other components verified were $\mathrm{Si}, \mathrm{Fe}, \mathrm{Au}, \mathrm{Ag}$, and $\mathrm{Cr}$.

Group ABZ presented a small percentage of nickel $(1.76 \%)$, which is statistically insignificant compared with the remaining groups; nevertheless, this percentage did not prove safe to patients with a history of allergy to metals. Nickel is regarded as cytotoxic, carcinogenic, allergenic and mutagenic; however, despite the few studies on this subject reported in the literature, the greatest problems found are hypersensitivity reactions. ${ }^{5}$ On the other hand, Park and Shearer ${ }^{1}$ observed that the release of nickel and chromium from orthodontic bands might sensitize patients to nickel and chromium, and, as such, may cause hypersensitivity reactions in patients with a prior history of hypersensitivity to these metals.

Nickel is known for stabilizing austenitic ferroalloys and acting as an anticorrosive agent. ${ }^{5}$ Nickel-free brackets would thus be more susceptible to corro- 
sion. Since polishing may influence ferroalloy corrosion, the authors of this study believe that nickel-free brackets (NF and RM) should present better polishing; nevertheless, this characteristic was observed only for the groups containing $\mathrm{Ni}$ (ABZ and RM). On the other hand, Mo also plays an important anticorrosive role when used in alloy steel, and can replace nickel in nickel-free alloys, as found in this study.

According to Rahilly and Price, ${ }^{12}$ the rough surface of orthodontic accessories may cause mechanical trauma from oral mucosa maceration, thus causing close contact of a patient's physical parts with products that may cause ferroalloy corrosion (release of ions), and establishing susceptibility to allergic reactions.

Pantuzo et al. ${ }^{3}$ assessed the relationship between a patient's medical history of allergy to metals and his/her allergic reaction to $\mathrm{Ni}$, and observed a definite correlation between sensitivity to $\mathrm{Ni}$ and allergy to metals. In addition, the authors found that nickel-free orthodontic accessories caused fewer allergic reactions.

Several authors assessed the release of metallic ions by orthodontic accessories. Huang et al. ${ }^{9}$ observed the release of $\mathrm{Ni}$ and $\mathrm{Mn}$ ions, as well as a great number of Fe ions from conventional metallic brackets in artificial saliva. This release is directly related to the period of degradation and to Fe content in the alloy, as verified in this study.

Petoumeno et al. ${ }^{5}$ concluded that the Ni concentration in a patient's saliva increased as the orthodontic sets were installed and the NiTi wires were applied; however, after 8 weeks, the concentration of Ni decreased to baseline levels. Kao and Huang ${ }^{16}$ associated the corrosion process with $\mathrm{pH}$, observing that the lower the $\mathrm{pH}$ of a solution, the greater the metal corrosion process.

\section{References}

1. Park HY, Shearer TR. In vitro release of nickel and chromium from simulated orthodontic appliances. Am J Orthod. 1983 Aug;84(2):156-9.

2. Eliades T, Anthanasiou AE. In Vivo Aging of Orthodontic Alloys:Implications for Corrosion Potential, Nickel Realese, and Biocompatibility. Angle Orthod. 2002 Jun;72(3):222-37.
The allergenic potential of other metals, such as $\mathrm{Cr}$ and $\mathrm{Co}$, should be emphasized, and a patient's allergic response to them, occurring simultaneously with a response to nickel, should be considered, since these metals are all components of orthodontic accessories. ${ }^{3}$ In this study, Cr was present in all brackets, and the Co in ABZ and NF groups, in a smaller amount.

Further studies should be conducted in order to assess the biodegradation of these brackets both in vivo and in vitro, in order to make metallic orthodontic brackets safer for clinicians to use.

\section{Conclusions}

Based on the results found in this study, the conclusions are:

a. The bracket surfaces for groups ABZ and RL were more homogeneous when observed through scanning electron microscopy, and presented stretch marks. The bracket surfaces of groups NF and RM were rougher, and had multiple imperfections, gaps, pores and also stretch marks.

b. Chemical composition analysis of the nickelfree brackets (groups NF and RM) are in accordance with the manufacturer's specifications, i.e., they contain no $\mathrm{Ni}$ in their composition, and are safe for patients with a medical record of allergy to this metal. Brackets from group ABZ had a low nickel percentage; however, no statistical difference was determined.

\section{Acknowledgements}

We would like to thank the Fundação Osvaldo Cruz (Fiocruz), especially the Scanning Electronic Microscopy Service, for supporting our study and letting us use their equipment.

\footnotetext{
3. Pantuzo MCG, Zenóbio EG, Marigo HA, Zenóbio MAF. Hypersensitivity to conventional and to nickel-free orthodontic brackets. Braz Oral Res. 2007 Oct-Dec;21(4):298-302.

4. Zinelis S, Annousaki O, Eliades T, Makou M. Elemental Composition of Brazing Alloys in Metallic Orthodontic Brackets. Angle Orthod. 2004 Jun;74(3):394-9.
} 
- Comparison surface characteristics and chemical composition of conventional metallic and Nickel-Free brackets

5. Petoumeno E, Kislyuk M, HoederathH, Keilig L, Bourauel C. Corrosion susceptibility and nickel realese of nickel titanium wires during clinical appliction. J Orofac Orthop. 2008 Nov;69(6):411-23.

6. Stenman E, Bergman M. Hypersensitivity reactions to dental materials in a referred group of patients. Scand J Dent Res. 1989 Feb;97(1):76-83.

7. Menezes LM, Souza RM, Dolci GS, Dedavid BA. Analysis of biodegradation of orthodontic brackets using scanning electron microscopy. Dental Press J Orthod. 2010 May-Jun;15(3):48-51.

8. Staffolani N, Damiani F, Lilli C, Guerra M, Staffolani NJ, Belcastro S, et al. Ion release from orthodontic appliances. J Dent. 1999 Aug;27(6):449-54.

9. Huang TH, Yen CC, Kao CT.Comparison of ion release from new and recycled orthodontic brackets. Am J Orthod Dentofacial Orthop. 2001 Jul;120(1):68-75.

10. Dolci GS, Menezes LM, Souza RM, Dedavid BA. Biodegradação de braquetes ortodônticos: avaliação da liberação iônica in vitro. R Dental Press Ortodon Ortop Facial. 2008 May-Jun;3(13):77-84.
11. Sfondrini MF, Cacciafesta V, Maffia E, Massironi S, Scribante A, Alberti G, et al. Chromium Release from New Stainless Steel, Recycled and Nickel-free Orthodontic Brackets. Angle Orthod. 2009 Mar;79(2):361-7.

12. Rahilly G, Price N. Nickel allergy and orthodontics. J Orthod. 2003 Jun;30(2):171-4.

13. Ehrnrooth M, Kerosuo H. Face and Neck Dermatitis from a stainless steel orthodontic appliance: case report. Angle Orthod. 2009 Nov;79(6):1194-6.

14. Vreeburg KJ, De Groot K, Von Bloomberg M, Scheper R. Induction of immunological tolerance by oral administration of nickel and chromium. J Dent Res. 1984 Feb;63(2):124-8.

15. Matasa CG. Attachment corrosion and its testing. J Clin Orthod. 1995 Jan;29(1):16-23.

16. Kao C, Huang T. Variations in surface characteristics and corrosion behavior of metal brackets and wires in different electrolyte solutions. Eur J Orthod. 2010 Oct;32(5):555-60. 